\title{
Atividade da enzima nitrato redutase em arroz de terras altas sob condições de estresse hídricos
}

\author{
Monique Carolina Nunes FERNANDES1, Flávia Barbosa Silva BOTELHO1, \\ Kamila Rezende Dázio de SOUZA¹, Gabrielle Carvalho PEREIRA¹, \\ Camila Soares Cardoso da SILVA ${ }^{1}$, Douglas Goulart CASTRO ${ }^{1 *}$
}

\begin{abstract}
${ }^{1}$ Departamento de Agricultura, Universidade Federal de Lavras, Lavras, Minas Gerais, Brasil. (Orcid: 0000-0002-3478-1082; 0000-0002-1675-0944; 0000-0001-9264-2382; 0000-0003-1859-1649; 0000-0003-3917-4588; *) *E-mail: douglasgoulartcastro@gmail.com (Orcid: 0000-0002-2478-0975)
\end{abstract}

Recebido em 20/01/2020; Aceito em 29/05/2020; Publicado em 31/07/2020.

\begin{abstract}
RESUMO: A assimilação de nitrogênio é um processo vital que controla o crescimento e desenvolvimento da planta, garantindo bons níveis de produtividade de grãos. A enzima nitrato redutase (NR) catalisa o primeiro passo enzimático da assimilação de nitrogênio pelas plantas superiores por meio da redução do nitrato $\left(\mathrm{NO}_{3}{ }^{-}\right)$ a nitrito $\left(\mathrm{NO}_{2}^{-}\right)$. Assim, objetivou-se estudar a atividade da enzima redutase do nitrato em genótipos de arroz de terras altas e correlacioná-la com os demais caracteres agronômicos. O experimento foi conduzido em dois ambientes distintos, com e sem irrigação suplementar. As análises de atividade enzimática foram realizadas em laboratório. Foram avaliados 20 genótipos de um experimento de VCU na safra 2014/2015. O delineamento experimental foi em blocos casualizados com três repetições. Foi obtida a quantidade de nitrito liberado pelos tecidos vegetais na solução de incubação ( $\mu$ moles $\mathrm{NO}_{2}^{-}$gmf $^{-1} \mathrm{~h}^{-1}$ ) em sete coletas realizadas aos 7, 14, 21, 28, 45, 75 e 100 dias após emergência (DAE), sempre no período da manhã, em todas as parcelas. Diante dos resultados, observou-se que a atividade da enzima NR, na cultura do arroz, é dependente do genótipo, do período de desenvolvimento vegetal e das condições ambientais, sendo de maior expressão no início do ciclo da cultura e em ambientes sem a ocorrência de estresse hídrico. A atividade da enzima RN não deve ser utilizada isoladamente para seleção indireta no caráter produtividade na cultura do arroz de terras altas, é necessário avaliar outras características que complementem à seleção.
\end{abstract}

Palavras-chave: Oryza sativa; nitrogênio; melhoramento de plantas; expressão enzimática.

\section{Activity of the nitrate reductase enzyme in upland rice under water stress conditions}

\begin{abstract}
Nitrogen uptake is a vital process that controls plant growth and development, ensuring great grain yield levels. The enzyme nitrate reductase (NR) catalyzes the first enzymatic step of nitrogen uptake by higher plants by reducing nitrate $\left(\mathrm{NO}_{3}^{-}\right)$to nitrite $\left(\mathrm{NO}_{2}^{-}\right)$. Thus, the objective was to study the activity of nitrate reductase enzyme in upland rice genotypes and to correlate it with other agronomic traits. The experiment was conducted in two distinct environments, with and without supplemental irrigation. The enzymatic activity assays were performed in the laboratory. Twenty genotypes of a VCU experiment in the 2014/2015 crop were evaluated. The experimental design was in randomized blocks with three replications. The amount of nitrite released by the plant tissues in the incubation solution ( $\mu$ moles $\mathrm{NO}_{2}^{-} \mathrm{gmf}^{-1} \mathrm{~h}^{-1}$ ) was obtained in seven collections performed at 7,14,21, 28, 45, 75 and 100 days after emergence (DAE). always in the mornings, in all installments. Given the results, it was observed that the activity of NR enzyme in rice culture is dependent on genotype, plant development period and environmental conditions, being more expressive at the beginning of the crop cycle and in environments without occurrence of water stress. The activity of the RN enzyme should not be used alone for indirect selection in the productivity character in the upland rice crop, it is necessary to evaluate other characteristics that complement the selection.
\end{abstract}

Keywords: Oryza sativa; nitrogen; plant breeding; enzymatic expression.

\section{INTRODUÇÃO}

A cultura do arroz exige grandes quantidades de nitrogênio $(\mathrm{N})$, sendo o segundo nutriente mais acumulado, seguido do potássio. Este nutriente participa como componente da clorofila, com grande participação no aumento da área foliar, aumentando consequentemente a eficiência na interceptação da radiação solar e taxa fotossintética e consequentemente em aumento da produtividade de grãos. Sendo assim, é importante que ele esteja disponível a planta para que não ocorra limitação da produtividade (FIDELIS et al., 2012).

A forma preferencial de $\mathrm{N}$ a ser absorvida e assimilada varia de acordo com a espécie de planta. Segundo Fageria (1984) a planta de arroz pode absorver indistintamente tanto o $\mathrm{N}$ em forma de $\mathrm{NO}_{3}$ como $\mathrm{NH}_{4}{ }^{+}$. Entretanto, a preferência pela utilização de uma das formas de $\mathrm{N}$ em 
detrimento da outra tem gerado vários trabalhos, cujos resultados ainda não são conclusivos (ARAÚJO et al., 2012).

A via de assimilação do nitrato é um processo biológico essencial, devido ao fato de ser a principal rota pela qual o nitrogênio inorgânico é incorporado em compostos orgânicos (FALCÃO, 2006). Consequentemente, a atuação da enzima nitrato redutase é de fundamental importância na incorporação de nitrogênio inorgânico em moléculas orgânicas complexas, sendo a etapa limitante nesse processo (SILVA et al., 2011).

A enzima NR catalisa o primeiro passo enzimático da assimilação de nitrogênio pelas plantas superiores por meio da redução do nitrato $\left(\mathrm{NO}_{3}{ }^{-}\right)$a nitrito $\left(\mathrm{NO}_{2}{ }^{-}\right)$(SANTOS et al., 2014). Parte do nitrogênio é absorvido pelas raízes na forma de nitrato, podendo ser reduzido, armazenado nos vacúolos ou translocado para a parte aérea, onde ocorrerá a redução ou armazenamento nos vacúolos foliares (TAIZ; ZEIGER, 2017). A redução de nitrato ocorre no citossol e envolve a ação da enzima RN, produzindo nitrito, o qual se fixa nos plastídeos nas raízes ou cloroplastos em folhas, e é reduzido à amônia por ação da enzima nitrito redutase $(\mathrm{NiR})$, a qual é fixada via glutamato sintase / glutamina sintase (GS/GOGAT) nos aminoácidos, glutamina e glutamato que servem de substrato para reações de transaminação, para a produção de aminoácidos necessários à síntese de proteínas (SILVA et al., 2011).

Justino et al. (2006) e Moro (2014) demonstraram diferenças entre genótipos de arroz em relação à atividade da enzima RN. A capacidade de genótipos de arroz em reduzir e incorporar nitrato é de fundamental importância para o sucesso da cultura em terras altas.

Atualmente o programa de melhoramento de arroz da Universidade Federal de Lavras (UFLA) em parceria com a Empresa Brasileira de Pesquisa Agropecuária (EMBRAPA Arroz e Feijão) e a Empresa de Pesquisa Agropecuária de Minas Gerais (EPAMIG), possui 20 genótipos em fase de ensaios de Valor de Cultivo e Uso (VCU), com potencial para serem lançados em breve como novas cultivares. Dessa forma objetivou-se com o presente trabalho, estudar a evolução da expressão da enzima $\mathrm{RN}$ nestes genótipos de arroz de terras altas, durante todo o ciclo de desenvolvimento da cultura e correlacioná-la com a produtividade final e demais caracteres agronômicos.

\section{MATERIAL E MÉTODOS}

O experimento foi conduzido, em dois ambientes distintos: um com irrigação suplementar, instalado na área experimental do Departamento de Agricultura (DAG) da Universidade Federal de Lavras - UFLA, Lavras, MG e outro sem irrigação suplementar situado no Centro de Desenvolvimento Científico e Tecnológico - Fazenda Muquém - Unidade Experimental, pertencente a UFLA, situada na região de Lavras.

Foram avaliados 20 genótipos (Tabela 1), pertencentes ao experimento de Valor de Cultivo e Uso (VCU), pertencente ao Programa de Melhoramento da UFLA em parceria com a EMBRAPA e EPAMIG, na safra 2014/2015.

Em ambos os ambientes, o delineamento experimental utilizado foi em blocos casualizados (DBC), com três repetições. As parcelas foram constituídas de cinco linhas de quatro metros, considerando as três linhas centrais como parcela útil e densidade de plantio de 80 sementes/metro.
Foram realizadas duas adubações, sendo uma realizada no plantio, utilizando $300 \mathrm{~kg} / \mathrm{ha}$ de 8-28-16 e uma adubação de cobertura, utilizando sulfato de amônio na proporção de 40 $\mathrm{kg} / \mathrm{ha}, 25$ dias após semeadura. Os demais tratos culturais foram os mesmos recomendados para a cultura do arroz de terras altas, de acordo com (UTUMI, 2008) exceto a aplicação de fungicida, pois o programa de melhoramento também avalia linhagens que são resistentes às doenças.

Tabela 1. Tratamentos utilizados no experimento.

Table 1. Treatments used in the experimente.

\begin{tabular}{cc}
\hline Identificação & Genótipos \\
\hline 1 & CMG 2162 \\
2 & CMG 2168 \\
3 & BRS Esmeralda \\
4 & CMG 2170 \\
5 & CMG 2172 \\
6 & BRS MG Caçula \\
7 & CMG 2185 \\
8 & CMG 2187 \\
9 & CMG 2188 \\
10 & CMG 2085 \\
11 & BRS Caravera \\
12 & BRS MG Relâmpago \\
13 & CMG 1511 \\
14 & CMG 2089 \\
15 & CMG 1896 \\
16 & CMG 2097 \\
18 & CMG 2093 \\
19 & CMG 1977 \\
20 & CMG 1509 \\
& CMG 1987 \\
\hline
\end{tabular}

A atividade da enzima RN foi avaliada "in vivo" nas folhas, utilizando-se o método descrito por Klepper et al. (1971), modificado por Meguro; Magalhães (1982). Como critério, foi estabelecido a coleta do material vegetal (folhas desenvolvidas com boa exposição solar) nos intervalos de 7 , 14, 21, 28, 45, 75 e 100 dias após emergência (DAE). Para realização desta análise, a coleta do material vegetal foi realizada entre as 9 e 10 horas da manhã, em dias com alta incidência de radiação solar, conforme Mazid et al. (2012).

As análises foram realizadas no Laboratório de Biologia e Fisiologia Molecular de Plantas, instalado no setor de Fisiologia Vegetal - Departamento de Biologia da Universidade Federal de Lavras - UFLA.

As folhas de cada parcela foram cortadas em torno de 5 $\mathrm{cm}$ acima do colmo e acondicionadas em papel alumínio, mantidas em caixa de isopor com gelo. No laboratório, o material vegetal, foi cortado em pequenos fragmentos, com tamanho médio aproximado de $2 \mathrm{~mm}$. Amostras de $500 \mathrm{mg}$ foram adicionadas a $5 \mathrm{ml}$, de meio de incubação contendo tampão fosfato de potássio $0,1 \mathrm{M}$ e $\mathrm{pH} 7,5$, n-propanol 1\% (v/v) e $\mathrm{KNO}_{3}$ a $0,1 \mathrm{M}$, em um béquer protegido da luz. Posteriormente, o tecido submerso na solução de incubação foi infiltrado à vácuo ( 2 minutos) por duas vezes e foram incubados em banho-maria a $30^{\circ} \mathrm{C}$ por 30 minutos. Depois do tempo de incubação, foi retirada, em duplicata, uma alíquota de $0,1 \mathrm{ml}$ de cada repetição e transferida para o meio de reação composto de $1 \mathrm{ml}$ de sulfanilamida $1 \%$ em $\mathrm{HCl}$ $1,5 \mathrm{~N}$, e $1 \mathrm{ml}$ de $\mathrm{N}-2$-naftil etileno $0,02 \%$. O volume foi completado para $4 \mathrm{ml}$ com água destilada. A concentração de nitrito produzida foi determinada em espectrofotômetro a $540 \mathrm{~nm}$, comparando os valores obtidos com uma curva padrão para esse íon, previamente estabelecida. A atividade 
da enzima RN foi expressa em micromol de nitrito produzido por grama de matéria fresca $(\mathrm{MF})$ por hora $\left(\mu \mathrm{mol} \mathrm{NO}_{2}-\mathrm{g}^{-1} \mathrm{MF}\right.$ $\left.\mathrm{h}^{-1}\right)$.

As demais características agronômicas avaliadas durante a condução do experimento foram: Número de dias para o florescimento - número de dias decorridos da semeadura ao florescimento médio, ou seja, quando a parcela apresentou aproximadamente $50 \%$ de plantas floridas; Altura de planta média, em cm, de cinco plantas da parcela, medida do solo à extremidade da panícula mais alta. A medida foi feita na época de florescimento das plantas, quando pelo menos 50\% das plantas já se encontravam nesse estádio; Massa de 1000 grãos (gramas) - realizada conforme metodologia descrita pela Regra de Análises de Sementes (BRASIL, 2009); Produtividade de grãos (kg/ha) - peso dos grãos da parcela após colheita e secagem para $13 \%$ de umidade.

Foram estimadas as correlações fenotípicas $\left(\mathrm{r}_{\mathrm{xy}}\right)$ entre $\mathrm{o}$ caráter atividade da enzima redutase do nitrato $e$ características agronômicas (dois a dois), conforme estimador:

$r_{x y}=\frac{\operatorname{Cov}_{x y}}{\left(\sigma_{x} \sigma_{y}\right)}$ em que: $\operatorname{COV}_{\mathrm{xy}}$ é a covariância entre as variáveis $\mathrm{X}$ e $\mathrm{Y}$, sendo $\mathrm{X}$ referente à atividade da enzima e $\mathrm{Y}$ referente às características agronômicas, e $\sigma_{\mathrm{x}}$ e $\sigma_{\mathrm{y}}$ os desvios fenotípicos das variáveis $\mathrm{X}$ e $\mathrm{Y}$, respectivamente.

Os dados coletados foram submetidos a análises estatísticas individuais e conjunta, utilizou-se o teste Scott e Knott a 5\% de probabilidade para comparação de médias e análise de regressão para fatores quantitativos com auxílio do software R (R CORE TEAM, 2017).

\section{RESULTADOS}

Durante as épocas de coleta observou-se um comportamento diferente entre os genótipos em relação a atividade enzimática (Tabela 2), havendo também uma interação significativa entre os ambientes x genótipos, pois, os genótipos apresentaram comportamentos distintos nos dois ambientes, visto que, no ambiente com irrigação suplementar, de maneira geral os genótipos apresentaram uma maior atividade enzimática.

Tabela 2. Média da atividade da enzimática (AE) $\left(\mu \mathrm{mol} \mathrm{NO} \mathrm{g}^{-1} \mathrm{MF} \mathrm{h}^{-1}\right)$ (considerando a média de todas as épocas de avaliação nos dois ambientes), produtividade de grãos (PROD) (kg/ha), número de dias para florescimento (NDF) (dias), altura de planta (AP) (m) e peso de mil grãos (PMG) (g) dos genótipos avaliados, considerando as médias com e sem irrigação suplementar.

Table 2. Average activity of the enzyme (AE) ( $\mu \mathrm{mol} \mathrm{NO} 2 \mathrm{~g}^{-1} \mathrm{MF} \mathrm{h}{ }^{-1}$ ) (considering the average of all periods of evaluation in both environments), grain yield (GY) (kg/ha), number of days to flowering (NDF) (days), plant height (PH) (m) and weight of thousand grains (WTG) (g) of the evaluated genotypes, considering the averages with and without supplementary irrigation.

\begin{tabular}{|c|c|c|c|c|c|c|c|c|c|c|}
\hline \multirow{2}{*}{ Genótipos } & \multicolumn{2}{|c|}{$\mathrm{AE}$} & \multicolumn{2}{|c|}{ PROD } & \multicolumn{2}{|c|}{$\mathrm{NDF}$} & \multicolumn{2}{|c|}{$\mathrm{AP}$} & \multicolumn{2}{|c|}{ PMG } \\
\hline & CI & SI & CI & SI & CI & SI & $\mathrm{CI}$ & SI & CI & SI \\
\hline 1 & $57,50 \mathrm{a}$ & $40,33 \mathrm{a}$ & $4038,89 \mathrm{a}$ & $6296,03 \mathrm{a}$ & $91,67 \mathrm{a}$ & $95,00 \mathrm{a}$ & $99,67 \mathrm{~b}$ & $100,00 \mathrm{~b}$ & $24,64 \mathrm{a}$ & $24,60 \mathrm{~b}$ \\
\hline 2 & $55,27 \mathrm{a}$ & $38,89 \mathrm{a}$ & $4707,14 \mathrm{a}$ & $4967,46 \mathrm{~b}$ & $82,00 \mathrm{c}$ & $93,00 \mathrm{a}$ & $112,67 \mathrm{a}$ & $96,33 \mathrm{~b}$ & $23,12 \mathrm{~b}$ & $23,70 \mathrm{c}$ \\
\hline 3 & $52,65 \mathrm{a}$ & $37,00 \mathrm{a}$ & 3734,92 a & $5496,03 \mathrm{a}$ & $92,00 \mathrm{a}$ & $92,33 \mathrm{a}$ & $99,33 \mathrm{~b}$ & $100,67 \mathrm{~b}$ & $20,97 \mathrm{c}$ & $22,35 \mathrm{c}$ \\
\hline 4 & $51,10 \mathrm{a}$ & $36,94 \mathrm{a}$ & $4282,54 \mathrm{a}$ & $5331,74 \mathrm{a}$ & $80,33 \mathrm{c}$ & $93,67 \mathrm{a}$ & $116,00 \mathrm{a}$ & $103,67 \mathrm{a}$ & $24,39 \mathrm{a}$ & $28,05 \mathrm{a}$ \\
\hline 5 & $45,58 \mathrm{~b}$ & $36,72 \mathrm{a}$ & $3442,06 \mathrm{a}$ & $5471,43 \mathrm{a}$ & $87,00 \mathrm{~b}$ & $93,00 \mathrm{a}$ & $99,00 \mathrm{~b}$ & $98,00 \mathrm{~b}$ & $23,28 \mathrm{~b}$ & $20,97 \mathrm{c}$ \\
\hline 6 & $45,37 \mathrm{~b}$ & $36,39 \mathrm{a}$ & $4965,08 \mathrm{a}$ & $4273,02 \mathrm{~b}$ & $90,67 \mathrm{a}$ & $91,00 \mathrm{a}$ & $110,33 \mathrm{a}$ & $102,67 \mathrm{a}$ & $21,96 \mathrm{c}$ & $23,56 \mathrm{c}$ \\
\hline 7 & $44,34 \mathrm{~b}$ & $34,92 \mathrm{a}$ & $4564,28 \mathrm{a}$ & $5752,38 \mathrm{a}$ & $88,33 \mathrm{~b}$ & $93,67 \mathrm{a}$ & $103,33 \mathrm{~b}$ & $104,00 \mathrm{a}$ & $25,40 \mathrm{a}$ & $27,04 \mathrm{a}$ \\
\hline 8 & $43,15 \mathrm{~b}$ & $34,65 \mathrm{a}$ & $4540,48 \mathrm{a}$ & $5180,16 \mathrm{a}$ & $87,00 \mathrm{~b}$ & $91,67 \mathrm{a}$ & $95,33 \mathrm{~b}$ & $110,00 \mathrm{a}$ & $22,35 \mathrm{~b}$ & $21,96 \mathrm{c}$ \\
\hline 9 & $41,97 \mathrm{~b}$ & $32,84 \mathrm{a}$ & $4025,40 \mathrm{a}$ & $6154,76 \mathrm{a}$ & $95,67 \mathrm{a}$ & $93,00 \mathrm{a}$ & $106,00 \mathrm{a}$ & $107,33 \mathrm{a}$ & $26,84 \mathrm{a}$ & $24,88 \mathrm{~b}$ \\
\hline 10 & $41,55 \mathrm{~b}$ & $30,22 \mathrm{a}$ & $5511,90 \mathrm{a}$ & 5548,41 a & $90,33 \mathrm{a}$ & $85,67 \mathrm{c}$ & $104,33 \mathrm{a}$ & $103,67 \mathrm{a}$ & $23,54 \mathrm{~b}$ & $27,49 \mathrm{a}$ \\
\hline 11 & $38,04 \mathrm{c}$ & $28,58 \mathrm{~b}$ & $4615,08 \mathrm{a}$ & $5298,41 \mathrm{a}$ & $95,00 \mathrm{a}$ & $94,67 \mathrm{a}$ & $101,67 \mathrm{~b}$ & $113,33 \mathrm{a}$ & $21,03 \mathrm{c}$ & $23,24 \mathrm{c}$ \\
\hline 12 & $36,92 \mathrm{c}$ & $27,25 \mathrm{~b}$ & $4248,41 \mathrm{a}$ & $5504,76 \mathrm{a}$ & $90,00 \mathrm{a}$ & $93,00 \mathrm{a}$ & $97,00 \mathrm{~b}$ & $105,00 \mathrm{a}$ & 28,11 a & $25,41 \mathrm{~b}$ \\
\hline 13 & $35,85 \mathrm{c}$ & $25,99 \mathrm{~b}$ & $5413,49 \mathrm{a}$ & $5203,97 \mathrm{a}$ & $92,00 \mathrm{a}$ & $93,33 \mathrm{a}$ & $115,67 \mathrm{a}$ & $94,67 \mathrm{~b}$ & $24,66 \mathrm{a}$ & $22,86 \mathrm{c}$ \\
\hline 14 & $34,74 \mathrm{c}$ & $25,40 \mathrm{~b}$ & $4465,08 \mathrm{a}$ & $5433,33 \mathrm{a}$ & $86,33 \mathrm{~b}$ & $89,67 \mathrm{~b}$ & $88,00 \mathrm{c}$ & $101,00 \mathrm{a}$ & $24,25 \mathrm{a}$ & $24,53 \mathrm{~b}$ \\
\hline 15 & $31,86 \mathrm{c}$ & $23,68 \mathrm{~b}$ & $4869,05 \mathrm{a}$ & $4880,95 \mathrm{~b}$ & $89,33 \mathrm{a}$ & $93,67 \mathrm{a}$ & $114,00 \mathrm{a}$ & $101,00 \mathrm{~b}$ & $23,14 \mathrm{~b}$ & $24,80 \mathrm{~b}$ \\
\hline 16 & $30,98 \mathrm{c}$ & $23,38 \mathrm{~b}$ & $5146,03 \mathrm{a}$ & $4495,24 \mathrm{~b}$ & $93,67 \mathrm{a}$ & $93,67 \mathrm{a}$ & $98,33 \mathrm{~b}$ & $98,33 \mathrm{~b}$ & $23,44 \mathrm{~b}$ & $23,32 \mathrm{c}$ \\
\hline 17 & $30,11 \mathrm{c}$ & $22,36 \mathrm{~b}$ & $5123,81 \mathrm{a}$ & $5490,47 \mathrm{a}$ & $92,00 \mathrm{a}$ & $91,67 \mathrm{a}$ & $113,33 \mathrm{a}$ & $110,67 \mathrm{a}$ & $22,91 \mathrm{~b}$ & $22,96 \mathrm{c}$ \\
\hline 18 & $29,95 \mathrm{c}$ & $21,70 \mathrm{~b}$ & $4582,54 \mathrm{a}$ & $5713,49 \mathrm{a}$ & $92,00 \mathrm{a}$ & $94,33 \mathrm{a}$ & $97,00 \mathrm{~b}$ & $104,33 \mathrm{a}$ & $22,86 \mathrm{~b}$ & $21,03 \mathrm{c}$ \\
\hline 19 & $28,67 \mathrm{c}$ & $17,55 \mathrm{~b}$ & $4197,62 \mathrm{a}$ & $4438,89 \mathrm{~b}$ & $84,00 \mathrm{c}$ & $93,33 \mathrm{a}$ & $89,67 \mathrm{c}$ & $97,33 \mathrm{~b}$ & $20,26 \mathrm{c}$ & $20,26 \mathrm{c}$ \\
\hline 20 & $24,89 \mathrm{c}$ & $15,31 \mathrm{~b}$ & $4254,76 \mathrm{a}$ & $4739,68 \mathrm{~b}$ & $93,00 \mathrm{a}$ & $93,00 \mathrm{a}$ & $85,00 \mathrm{c}$ & $91,00 \mathrm{~b}$ & $24,64 \mathrm{a}$ & $25,44 \mathrm{~b}$ \\
\hline Média & 40,02 & 29,50 & 4536,43 & 5283,53 & 89,62 & 92,62 & 102,28 & 102,15 & 23,57 & 23,92 \\
\hline
\end{tabular}

Foram estimadas as correlações fenotípicas entre a atividade da enzima NR com os demais caracteres agronômicos avaliados, com o intuito de obter informações sobre sua influência no desempenho fenotípico dos genótipos de arroz de terras altas (Tabela 3).

No desdobramento dos ambientes em relação às coletas, observou-se que no ambiente sem estresse a atividade da enzima foi superior a atividade demonstrada no ambiente com estresse hídrico até a sexta coleta. Na última coleta, o desempenho da NR no ambiente desfavorável foi maior (Figura 1).

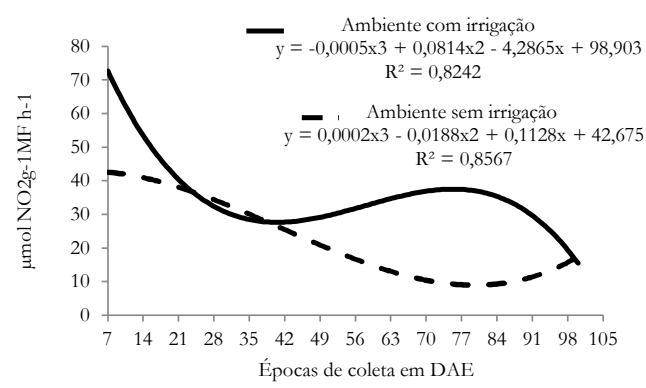

Figura 1. Evolução da atividade da enzima redutase do nitrato durante todo o ciclo da cultura em ambos ambientes, considerando a média dos tratamentos e média das coletas. 
Figure 1. Evolution of the activity of the nitrate reductase enzyme throughout the culture cycle in both environments, considering the average of treatments and the average of collections.

Tabela 3. Estimativas das correlações entre as características produtividade de grãos (PROD) $(\mathrm{kg} / \mathrm{ha})$, número de dias para florescimento (NDF) (dias), altura de planta (AP) (m) e peso de mil grãos (PMG) (g) e a atividade da enzima nitrato redutase (AE), considerando a média de todos os tratamentos nos dois ambientes e a média de todos os tratamentos nas sete épocas de avaliação da atividade da enzima nos dois ambientes.

Table 3. Estimates of correlations between grain yield characteristics (GY) (kg/ha), number of days to flowering (NDF) (days), plant height $(\mathrm{PH})(\mathrm{m})$ and weight of thousand grains (WTG) $(\mathrm{g})$ and the activity of the enzyme nitrate reductase (AE), considering the average of all treatments in both environments and the average of all treatments in the seven periods of evaluation of enzyme activity in both environments.

\begin{tabular}{cccccc}
\hline \multicolumn{6}{c}{ Coeficientes de Correlação } \\
\hline AE & PROD & NDF & AP & PMG \\
\hline PROD & - & $-0,15^{\text {ns }}$ & $-0,32^{\text {ns }}$ & $0,27^{\text {ns }}$ & $0,15^{\text {ns }}$ \\
NDF & & - & $0,22^{\text {ns }}$ & $0,48^{*}$ & $0,11^{\text {ns }}$ \\
AP & & & - & $-0,15^{\text {ns }}$ & $-0,02^{\text {ns }}$ \\
PMG & & & - & $0,09^{\text {ns }}$ \\
${ }^{*}$, significativo a $5 \%$. ${ }^{\text {ns }}$, não significativo & & & - \\
\hline
\end{tabular}

\section{DISCUSSÃO}

Para a característica produtividade de grãos, na análise conjunta os tratamentos apresentaram uma média geral de $4.909,98 \mathrm{~kg} / \mathrm{ha}$. Houve uma amplitude de variação de 874,14 $\mathrm{kg} / \mathrm{ha}$ entre as linhagens CMG 1896 e BBRS MG Caravera. No desdobramento dos ambientes, os tratamentos sem irrigação suplementar apresentaram as maiores médias de produtividade de grãos. Observou-se que 11 genótipos obtiveram média de produtividade superior à média geral, com valores variando de 4.915 .47 e $5.784,12 \mathrm{~kg} / \mathrm{ha}$.

Para a característica peso de mil grãos (Tabela 2), os resultados foram significativos e os tratamentos se dividiram em quatro grupos distintos, apresentando média geral de 23,75g com amplitude de variação de 20,26g (CMG 2172) e 28,07g (CMG 2089).

Para número de dias para o florescimento, observou-se uma oscilação de 83 (BRSMG Caçula) a 94 dias (CMG 2162; CMG 2093) com média geral de 91 dias. E considerando a característica altura média de planta a média geral foi de 102 $\mathrm{cm}$, com variação de $88 \mathrm{~cm}$ (CMG 2168) a $113 \mathrm{~cm}$ (CMG 1509).

As características produtividade de grãos e altura de plantas apresentaram correlação significativa, com um valor de 0,48 . Isso indica que na maioria dos casos, as plantas mais altas também são as mais produtivas, e a seleção de genótipos mais produtivos vislumbra a uma seleção indireta, correlacionada, de plantas mais altas, o que não é desejável em um programa de melhoramento de arroz, pois plantas mais altas acamam com maior facilidade (KONO, 1995; WATANABE, 1997)

A atividade da enzima NR é favorecida em condições ideais de cultivo, sendo a água um dos principais elementos participantes do metabolismo do nitrogênio associado ao metabolismo do carbono para ativação da enzima (TAIZ; ZEIGER, 2017).

Moro et al. (2014), que obteve resultados similares ao presente trabalho, demonstraram avaliando dez cultivares de arroz de terras altas, que a atividade da NR foi reduzida ao longo do ciclo das cultivares. Contudo, contraria a teoria de Malavolta (1980) afirmou que a atividade da enzima NR é baixa no início do desenvolvimento do arroz e aumenta com o decorrer do tempo. Todavia, vale a pena ressaltar, que os genótipos atuais, apresentam diferentes combinações genotípicas, logo um comportamento agronômico frente às condições ambientais diferenciado.

Santos et al (2014) observou em cana de açúcar que a atividade da NR é mais elevada nas plantas jovens formadas pela brotação da soqueira, e diminui com o desenvolvimento da planta, o que corrobora com os resultados obtidos neste trabalho.

Esses resultados pressupõem que o gene que codifica à enzima NR deve ser mais facilmente acionado em condições ambientais favoráveis à sua expressão, entretanto, outros trabalhos já elucidam esse fato. Segundo Chaves et al. (2002), algumas mudanças metabólicas como a redução na atividade da enzima NR ocorrem como resultado do estresse hídrico, sendo que, essas mudanças contribuem para manutenção da pressão osmótica dentro das células fotossintéticas através do aumento da concentração de nitrato e redução do fluxo de carboidrato. Logo, a redução do crescimento foliar também contribui para o acúmulo de soluto e ajustamento osmótico. A água tem grande importância na manutenção da hidratação do protoplasma (MORAIS et al., 2003) e redistribuição de fotoassimilados e compostos nitrogenados (LEMOS et al., 2010).

O aumento na atividade da NR não necessariamente indica aumento de produtividade (MACHADO et al., 2013). A análise da atividade desta enzima realizada em loco condiz com o ambiente e a atividade metabólica no momento analisado, sendo a produtividade influenciada por diferentes fatores. Segundo Lafitte et al. (2006), as diferenças de produtividade de grãos podem ser atribuídas à capacidade de cada genótipo em produzir e acumular fotoassimilados para serem convertidos em matéria seca e produção de grãos ao final da fase de maturação fisiológica. Nunes et al. (2012) em seu experimento com 20 genótipos de arroz de terras altas, comparando dois ambientes, com e sem estresse hídrico, também obteve genótipos que foram superiores estatisticamente em produtividade de grãos aos demais na condição com estresse.

A massa de grãos é uma característica variável entre genótipos, dependendo da condição do ambiente. De acordo com apresentado por Nunes et al. (2012) linhagens com baixa disponibilidade de água durante a fase de maturação da cultura, principalmente nos dias posteriores ao florescimento, podem ter o processo de enchimento de grãos prejudicado. Assim como, os dias para o florescimento são características influenciadas pelo genótipo e as condições do ambiente. Heinemann; Stone (2009), avaliaram quatro cultivares de arroz de terras altas em ambiente irrigado e ambiente com estresse e obtiveram média de 76 dias para o florescimento no ambiente irrigado e 83 dias para o ambiente com estresse, resultados inferiores aos obtidos no presente trabalho. O que reforça o fato, desta característica ser influenciada pelo genótipo e condições ambientais.

Já a altura média de plantas, é uma característica dependente de um conjunto de fatores (FIDELIS et al., 2016), sendo eles: temperatura, luminosidade e umidade, o que faz com que sua expressão se dê de forma variada.

Para a correlação genética, quando duas características apresentam correlação favorável, é possível obter ganhos 
para um deles por meio da seleção indireta no outro caráter associado. Em alguns casos, a seleção indireta, com base na resposta correlacionada, pode levar a progressos mais rápidos do que a seleção direta do caráter desejado. Contudo, se um caráter se correlacionar negativamente com alguns e positivamente com outros, é preciso tomar o cuidado de, ao selecionar para um deles, não provocar mudanças indesejáveis em outros (FALCONER; MACKAY, 1996).

Em seu trabalho sobre eficiência produtiva de cultivares de arroz, Guimarães et al. (2008) analisou a correlação entre a produtividade e componentes agronômicos (índice de colheita, perfilhos férteis, massa de 100 grãos, esterilidade de espiguetas, grãos por panículas e altura) das cultivares trabalhadas e obteve como resultado o índice de colheita, a massa de 100 grãos e a esterilidade de espiguetas apresentando maior correlação com a produtividade de grãos. Resultados estes, diferentes dos obtidos no presente trabalho. Estes resultados podem ter ocorrido em virtude dos diferentes genótipos, e devido as próprias diferenças ambientais.

Entretanto, em trabalho desenvolvido com arroz de terras altas, Dalchiavon et al. (2012) não encontrou uma correlação significativa entre produtividade de grãos e peso de mil grãos, concordando com os resultados obtidos neste trabalho.

\section{CONCLUSÕES}

A atividade da enzima NR, na cultura do arroz, é dependente do genótipo, do período de desenvolvimento vegetal e das condições ambientais, sendo de maior expressão no início do ciclo da cultura e em ambientes sem a ocorrência de estresse hídrico.

A atividade da enzima NR não é eficaz isoladamente para seleção indireta somente para o caráter produtividade de grãos na cultura do arroz de terras altas, sendo necessário avaliar outras características que complementem à seleção.

\section{AGRADECIMENTOS}

Este trabalho foi financiado pelo Conselho Nacional de Desenvolvimento Científico e Tecnológico (CNPq), Coordenação de Aperfeiçoamento de Pessoal de Nível Superior (CAPES), Fundação de Amparo à Pesquisa de Minas Gerais (FAPEMIG), Empresa Brasileira de Pesquisa Agropecuária (Embrapa), Empresa de Pesquisa Agropecuária de Minas Gerais (EPAMIG) e Universidade Federal de Lavras (UFLA).

\section{REFERÊNCIAS}

ARAÚJO, J. L.; FAQUIN, V.; VIEIRA, N. M. B.; OLIVEIRA, M. V. C.; SOARES, A. A.; RODRIGUES, C. R.; MESQUITA, A. C. Crescimento e produção do arroz sob diferentes proporções de Nitrato e de Amônio - Revista Brasileira de Ciência do Solo, Viçosa, v. 36, n. 3, p. 921-930, 2012. DOI: https://dx.doi.org/10.1590/S0100-06832012000300022

BRASIL_MINISTÉRIO DA AGRICULTURA E REFORMA AGRÁRIA. Regras para análise de sementes. Brasília: DNDV/CLAV, 2009. 365 p.

CHAVES, M. M.; PEREIRA, J. S.; MAROCO, M. L.; RICARDO, C. P. P.; OSORIO, M. L.; CARVALHO, I.; FARIA, T.; PINHEIRO, C. How plants cope with water stress in the field. Photosynthesis and Growth. Annals of
Botany, London, v. 89, n. 7, p. 907-916, 2002. DOI: https://doi.org/10.1093/aob/mcf105

DALCHIAVON, F. C.; CARVALHO, M. P.; COLETTI, A. J.; CAIONE, G.; SILVA, A. F.; ANDREOTTI, M.; Correlação linear entre componentes da produção e produtividade do arroz de terras altas em sistema plantio direto. Semina: Ciências Agrárias, Londrina, v. 33, n. 5, p. 1629-1642, 2012.

FAGERIA, N. K. Adubação e nutrição mineral da cultura de arroz. Rio de Janeiro: Campus, 1984. 341 p.

FALCÃO, V. R. Aspectos moleculares de nitrato redutase da macroalga marinha Gracilaria tenuistipitata (RHODOPHYTA): sequenciamento do gene e estudo da expressão do RNA mensageiro. 2006. 132f. Tese (Doutorado em Química) - Curso de Pós-graduação em Química, Universidade de São Paulo, 2006.

FALCONER, D. S.; MACKAY, T. F. C. Introduction to quantitative genetics. 4. ed. New York: Longman, 1996. $464 \mathrm{p}$.

FIDELIS, R. R.; RODRIGUES, A. M.; SILVA, G. F.; BARROS, H. B.; PINTO, L. C.; AGUIAR, R. W. S.; FIDELIS, R. R. Eficiência do uso de nitrogênio em genótipos de arroz de terras altas. Pesquisa Agropecuária Tropical, Goiânia, v. 42, n. 1, p. 124-128. 2012. DOI: https://dx.doi.org/10.1590/S198340632012000100018

FIDELIS, R. R.; TONELlO, L. P.; VELOSO, D. A.; SANTOS, V. B.; BARROS, H. B. Comportamento de cultivares de arroz em condições de baixo nível tecnológico. Brazilian Journal of Applied Technology for Agricultural Science, Guarapuava, v. 9, n. 2, p. 7-17, 2016.

GUIMARÃES, C. M.; STONE, L. F.; NEVES, P. de C. F. Eficiência produtiva de cultivares de arroz com divergência fenotípica. Revista Brasileira de engenharia agrícola e ambiental, Campina Grande, v. 12, n. 5, p. 465-470. 2008. DOI: http://dx.doi.org/10.1590/S1415-43662008000500004

HEINEMANN, A. B.; STONE, L. F. Efeito da deficiência hídrica no desenvolvimento e rendimento de quatro cultivares de arroz de arroz de terras altas. Pesquisa Agropecuária Tropical, Goiânia, v. 39, n. 2, p. 134-139, 2009.

JUSTINO, G. C.; CAMBRAIA, J.; OLIVA, M. A.; OLIVEIRA, J. A. Absorção e redução de nitrato em duas cultivares de arroz na presença de alumínio. Pesquisa Agropecuária Brasileira, Brasília, v. 41, n. 8, p. 12851290, 2006. DOI: https://dx.doi.org/10.1590/S0100204X2006000800011

KLEPPER, L.; FLESHER, D. E.; HAGEMAN, E. H. Generation of reduced nicotinamide adenine dinucleotide for nitrate reduction in green leaves. Plant Physiology, Rockville, v. 48, p. 580-90, 1971. DOI: https://dx.doi.org/10.1104/pp.48.5.580

KONO, M. Phsysiological aspects of lodging. In: MATSUO, T.; KUMAZAWA, K..; ISHII, R.; ISHIHARA, K.; HIRATA, H. Science of the rice plant. Tokyo, Japan: Nobunkyo, 1995. v. 2. cap. 4. p.971-982.

LAFITTE, H. R.; LI, Z. K.; VIJAYAKUMAR, C. H. M.; GAO, Y. M.; SHI, Y.; XU, J. L.; FU, B. Y.; YU, S. B.; ALI, A. J.; DOMINGO, J.; MAGHIRANG, R.; TORRES, R.; MACKILL, D. Improvement of rice drought tolerance through backcross breeding: 
evaluation of donors and selection in drought nurseries. Field Crops Research, Amsterdam, v. 97, n. 1, p. 77-86, 2006.

DOI: https://dx.doi.org/10.1016/j.fcr.2005.08.017

LEMOS, C. L.; MATSUMOTO, S. N.; VIANA, A. E. S.; COELHO, R. A, CÉSAR, F. R. C. F. Metabolismo de nitrogênio em dois sistemas de cultivo de café sob veranico da estação úmida. Revista Ceres, Viçosa, v. 57, n. $1, \quad$ p. $34-41, \quad 2010$. DOI: http://dx.doi.org/10.1590/S0034-737X2010000100007

MACHADO, V. J.; SOUZA, C. H. E.; RIBEIRO, V. J.; CAIXETA, C. G. Atividade da redutase do nitrato e desenvolvimento de milho irrigado adubado com fosfato monoamônico polimerizado. Revista Brasileira de Milho e Sorgo, Sete Lagoas, v. 12, n. 3, p. 203-213, 2011. DOI: $\quad$ https://doi.org/10.18512/19806477/rbms.v12n3p203-213

MALAVOLTA, E. Elementos de nutrição mineral de plantas. São Paulo: Agronômica Ceres, 1980. 251 p.

MAZID, M.; KHAN, T. A.; MOHAMMAD, F. Role of nitrate reductase in nitrogen fixation under photosynthetic regulation. World Journal of Pharmaceutical Research, Sofia, v. 1, n. 3, p. 386-414, 2012.

MEguro, N. E.; MAGAlhães, A. C. Atividade da redutase de nitrato em cultivares de café. Pesquisa Agropecuária Brasileira, Brasília, v. 17, n. 12, p. 172531, 1982.

MORAIS, H.; MARUR, C. J.; CARAMORI, P. H.; RIBEIRO, A. M. de A.; GOMES, J. C. Características fisiológicas e de crescimento de cafeeiro sombreado com guandu e cultivado a pleno sol. Pesquisa Agropecuária Brasileira, Brasília, v. 38, n. 10, p. 1131-1137, 2003. DOI: https://dx.doi.org/10.1590/S0100204X2003001000001

MORO, E.; CRUSCIOL, C. A. C.; NASCENTE, A. S.; CANTARELLA, H. Atividade da enzima nitrato redutase em cultivares de arroz de terras altas. Agrarian, Dourados, v. 7, n. 26, p. 602-607, 2014.
NUNES, T. V.; ADORIAN, G. C.; TERRA, T. G. R.; LEAL, T. C. A. B.; SANTOS, A. C.; RAMOS, P. S. Aspectos produtivos de linhagens de arroz de terras altas sob déficit hídrico. Revista Brasileira de Ciências Agrárias, Recife, v. 7, n. 1, p. 51-57, 2012. DOI: http://dx.doi.org/10.5039/agraria.v7i1a1411

R CORE TEAM. R: A Language and Environment for Statistical Computing. Vienna, Austria, 2017.

SANTOS, C. L. R.; CAZETTA, J. O.; SARAN, L. M.; SANCHES, A. Otimização da análise da atividade da redutase do nitrato e sua caracterização em folhas de cana de açúcar. Pesquisa Agropecuária Brasileira, Brasília, v. 49 , n. 5, p. 384-394, 2014. DOI: http://dx.doi.org/10.1590/S0100-204X2014000500008

SILVA, S. M.; OLIVEIRA, L. J.; FARIA, F. P.; REIS, E. F.; CARNEIRO, M. A. C.; SILVA, S. M. Atividade da enzima nitrato redutase em milho cultivado sob diferentes níveis de adubação nitrogenada e potássica. Ciência Rural, Santa Maria, v. 41, n. 11, p. 1931-1937, 2011. http://dx.doi.org/10.1590/S010384782011005000136

TAIZ, L.; ZEIGER, E. Fisiologia e desenvolvimento vegetal. 6. ed. Porto Alegre: Artmed, 2017. 719 p.

TERRA, T. G. R.; LEAL, T. C. A.; RANGEL, P. H. N.; Oliveira, A. B. B. Características de tolerância à seca em genótipos de uma coleção nuclear de arroz de terras altas, Pesquisa Agropecuária Brasileira, Brasília, v. 50, n. 9, p. 788-796, $2015 . \quad$ DOI: http://dx.doi.org/10.1590/S0100-204X2015000900007

UTUMI, M. M. Sistema de produção de arroz de terras altas. Embrapa Rondônia-Sistema de Produção (INFOTECA-E), 2008.

WATANABE, T. Lodging resistance. In: MATSUO, T.; KUMAZAWA, K.; ISHII, R.; ISHIHARA, K.; HIRATA, H. Science of the rice plant. Tokyo, Japan: Nobunkyo, 1997. v. 3. p.567-577. cap. 4. 